\title{
Pengukuran Metrik Kompleksitas Model Proses Bisnis Sekolah
}

\author{
Muhammad Ainul Yaqin', Dicky Eka Asia Pratama², Mohammad Rofi'uruttab³, Ilman Dwi \\ Cahya ${ }^{4}$ \\ 1,2,3,4Teknik Informatika, UIN Maulana Malik Ibrahim Malang \\ Jl. Gajayana 50 Malang 65144, Telp: (0341) 551354 \\ 1yaqinov@ti.uin-malang.ac.id,216650073@student.uin-malang.ac.id,316650047@student.uin- \\ malang.ac.id, ${ }^{4} 16650083 @$ student.uin-malang.ac.id
}

\begin{abstract}
School as an institution that has a primary mission to educate and develop the character of the nation through a series of learning activities. School is an organization whose success goals are largely determined by the leadership style and organizational paradigm that is shared by all school components. Schools as organizations have business processes as a collection of procedures or activities that can define business objectives or objectives, generally in the context of organizational structures that can define functional roles and relationships within the organization. The main purpose of BPMN is to provide a notation that is easy to use and can be understood by everyone involved in business, which includes business analysts who model business processes, technical developers who build systems that carry out business, and various levels of management that must be able to read and understand processes diagram quickly so that it can help in decision making. To measure the complexity of a business process, complexity metrics are measured. This study uses the Cognitve Information Complexity Measure (CICM) method. Researchers took 3 SOPs of national education standards namely SOP curriculum development resulting in a standard value of complexity 425.1496, SOP for the Learning Process produced a standard value of complexity 2091.333 and SOP for Teacher Recruitment resulted in a standard value of complexity of 1145.49.
\end{abstract}

Keywords: CICM, business process model, complexity metric

\begin{abstract}
Abstrak
Sekolah sebagai institusi yang memiliki misi utama untuk mencerdaskan dan membangun karakter anak bangsa melalui serangkaian kegiatan belajar Sekolah merupakan suatu organisasi yang keberhasilan tujuannya sangat ditentukan oleh gaya kepemimpinan dan paradigma organisasi yang dipegang bersama oleh segenap komponen sekolah. Sekolah sebagai organisasi mempunyai proses bisnis sebagai kumpulan prosedur atau aktivitas yang dapat mendefinisikan objektif atau tujuan bisnis, umumnya dalam konteks struktur organisasi yang dapat mendefinisikan peranan dan hubungan fungsional pada organisasi tersebut. Tujuan utama dari BPMN adalah menyediakan notasi yang mudah digunakan dan bisa dimengerti oleh semua orang yang terlibat dalam bisnis, yang meliputi bisnis analis yang memodelkan proses bisnis, pengembang teknik yang membangun sistem yang melaksanakan bisnis, dan berbagai tingkatan manajemen yang harus dapat membaca dan memahami proses diagram dengan cepat sehingga dapat membantu dalam pengambilan keputusan. Untuk mengukur kompleksitas suatu proses bisnis dilakukan pengukuran metrik kompleksitas. Penelitian ini menggunakan metode Cognitve Information Complexity Measure (CICM). Peneliti mengambil 3 sop standar nasional pendidikan yaitu SOP pengembangan kurikulum menghasilkan nilai standar kompleksitas 425,1496, SOP Proses Pembelajaran menghasilkan nilai standar kompleksitas 2091,334 dan SOP Perekrutan Guru menghasilkan nilai standar kompleksitas 1145,49.
\end{abstract}

Kata kunci: CICM, model proses bisnis, metrik kompleksitas 
Jurnal Riset Sistem Informasi Dan Teknik Informatika (JURASIK) Volume 5 Nomor 2 Agustus, pp 217-226

ISSN: 2527-5771/EISSN: 2549-7839

https://tunasbangsa.ac.id/ejurnal/index.php/jurasik

\section{PENDAHULUAN}

Pengukuran ini dibuat sedemikian rupa agar proses dalam pembentukan sekolah lebih efisien dalam menangani masalah-masalah yang ada dalam proses pendidikan [1]. Sebuah proses yang efisien dapat mempermudah pekerjaan namun biasanya terdapat sebuah masalah yang harus diselesaikan secara kompleks dimana setiap hal harus diperkiraan secara sedemikian rupa. Dalam hal ini secara harfiah juga digunakan sebagai tolak ukur sebuah model didalam sekolah. Dan juga menjadi faktor-faktor terjadinya hambatan saat memulai hal baru.

Sekolah sebagai institusi yang memiliki misi utama untuk mencerdaskan dan membangun karakter anak bangsa melalui serangkaian kegiatan belajar Sekolah merupakan suatu organisasi yang keberhasilan tujuannya sangat ditentukan oleh gaya kepemimpinan dan paradigma organisasi yang dipegang bersama oleh segenap komponen sekolah. mengajar dan pendukungnya mestinya tidak menutup diri untuk belajar [2]. Proses bisnis adalah instrumen kunci untuk mengatur kegiatan ini dan untuk meningkatkan pemahaman tentang keterkaitan mereka. Kegiatan proses bisnis dapat dilakukan oleh karyawan perusahaan secara manual atau dengan bantuan sistem informasi [1].

Workflow Management Coalition (WfMC) mendefinisikan proses bisnis sebagai kumpulan prosedur atau aktivitas yang dapat mendefinisikan objektif atau tujuan bisnis, umumnya dalam konteks struktur organisasi yang dapat mendefinisikan peranan dan hubungan fungsional pada organisasi tersebut [3]. BPMN adalah singkatan dari Business Process Modeling Notation, yaitu suatu metodologi baru yang dikembangkan oleh Business Process Modeling Initiative sebagai suatu standar baru pada pemodelan proses bisnis, dan juga sebagai alat desain pada sistem yang kompleks seperti sistem $e$-Business yang berbasis pesan (message-based).[3] Tujuan utama dari BPMN adalah menyediakan notasi yang mudah digunakan dan bisa dimengerti oleh semua orang yang terlibat dalam bisnis, yang meliputi bisnis analis yang memodelkan proses bisnis, pengembang teknik yang membangun sistem yang melaksanakan bisnis, dan berbagai tingkatan manajemen yang harus dapat membaca dan memahami proses diagram dengan cepat sehingga dapat membantu dalam pengambilan keputusan. BPMN memugkinkan proses bisnis dipetakan ke bahasa eksekusi bisnis berbasis XML seperti BPEL4WS (Business Process Execution Language for Web Service) dan BPML (Business Process Modeling Language) [4].

Pada penelitan [5] Salah satu metrik kompleksitas perangkat lunak yang paling populer untuk mengukur kompleksitas suatu program adalah kompleksitas siklomatik (CC), yang dikembangkan oleh McCabe pada tahun 1976 [6]. Teori yang mendasari adalah bahwa semakin besar jumlah jalur melalui modul, semakin tinggi kompleksitasnya. Sanjaya [3] bahwa tujuan dari pembuatan perangkat lunak adalah untuk menciptakan perangkat lunak yang berkualitas, sama halnya pada proses bisnis. Tujuan dari pengukuran kompleksitas model proses bisnis adalah jalan awal untuk menciptakan proses bisnis yang berkualitas, efektif dan efisien. Metrik kompleksitas ialah salah satu perhitungan yang ada dimana perhitungan yang terjadi bukan hanya sekedar menghitung sesuatu. Perhitungan tersebut memiliki berbagaia methodologi yang terkait didalam suatu pembahasan yang 
terkait pada proyek suatu judul yang digunakan. Dalam hal prosesnya memiliki berbagai tahapan diantaranya tahapan dengan minimal tahapan yang terjadi 2 bagian. Cara ini sering diapakai ketika seseorang memiliki data yang detail dan menhasilkan suatu standar dari apa yang dihitung denga kata lain proses yang terjadi didalamnya sering dipakai untuk menentukan suatu proses proses.

Pada Penelitan ini menggunakan Cognitive Information Complexity measure (CICM) untuk mengukur model proses bisnis sekolah. Proses bisnis sekolah berdasarkan Standar Nasional Pendidikan. Tujuan penelitian ini adalah untuk mengetahui seberapa komplek proses bisnis sekolah berdasarkan standar nasional pendidikan.

\section{METODOLOGI PENELITIAN}

\subsection{Rancangan Penelitian}

Penelitian ini bertujuan untuk mengukur kompleksitas model proses bisnis sekolah. Alur tahapan untuk melakukan penelitian yaitu studi literatur, pengumpulan data, analisis data, usulan SOP, pemodelan proses bisnis, pengukuran model proses bisnis dan pengukuran model proses bisnis bisa dilihat pada gambar 1 .

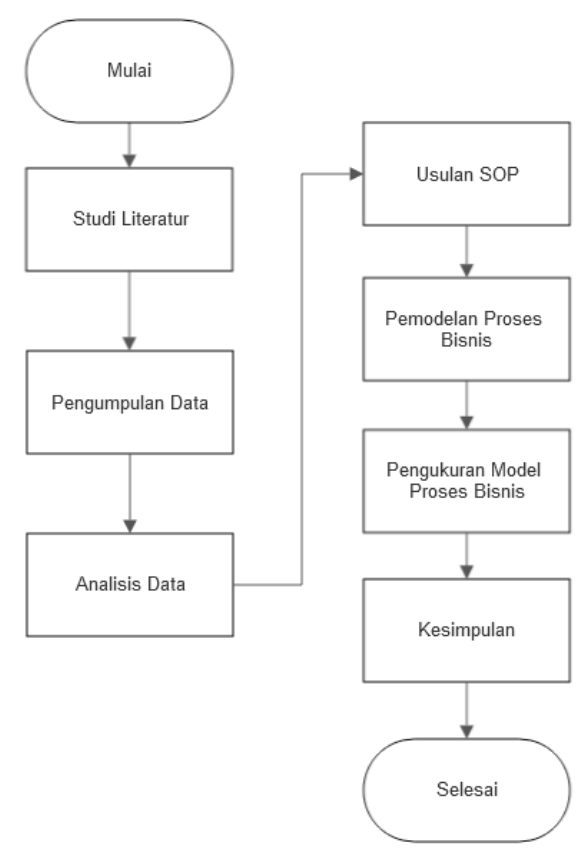

Gambar 1. Flowchart Rancangan Penelitian

Untuk usulan SOP dan pemodelan proses bisnis bekerja sama dengan peneliti lain yang melakukan penelitan pemodel proses bisnis sekolah. Peneliti hanya melakukan perhitungan metrik kompleksitas pemodelan yang sudah dibuat oleh peneliti lain tersebut.

\subsection{Teknik Pengumpulan Data}

Pada penelitian ini menggunakan pengumpulan data menggunakan studi dokumen, wawancara dan Studi Dokumen. Pengumpulan data yang dilakukan 
dengan mempelajari jurnal yang terkait, dokumen cetak maupun online untuk informasi yang berhubungan dengan masalah penelitian beserta objek yang diteliti.

\subsection{Sumber Data}

Pada penelitian ini data yang digunakan sumber data yaitu data primer dan data sekunder

a) Data Primer

Data primer yang digunakan yaitu data dari penelitian yang terkait. data ini didapat dari penelitian lain yang meneliti tentang pemodelan proses bisnis sekolah.

b) Data Sekunder

Data sekunder adalah data yang didapat secara tidak langsung atau data tersebut telah dikumpulkan oleh pihak lain yang dikumpulkan peneliti sebagai penunjang pembuatan penelitian. Atau data-data yang tersusun dalam bentuk dokumen seperti jurnal yang terkait pada topik penelitian.

\section{HASIL DAN PEMBAHASAN}

Pada bagian ini diberikan hasil penelitian yang dilakukan sekaligus dibahas secara komprehensip. Hasil bisa berupa gambar, grafik, tabel dan lain-lain yang mempermudah pembaca paham dan diacu di naskah. Jika bahasan terlalu panjang dapat dibuat sub-sub judul, seperti contoh berikut.

\subsection{Cognitive Information Complexity Measure (CICM)}

Pada penelitian [2] didefinisikan sebagai, "produk hitungan informasi tertimbang dari perangkat lunak (WICS) dan bobot kognitif atau cognitive weight $(W c)$ BCS dalam perangkat lunak. Untuk Penelitian ini, rumus ini diimplementasikan pada model proses bisnis, sehingga objek penelitian dariperangkt lunak diubah menjadi BPMN dan line of code dianalogikan menjadi suatu metrik activity. Untuk pelambangan rumusnya yaitu.

$$
C I C M=W I C S * W C
$$

Di mana WICS adalah jumlah dari penghitungan informasi terbobot (WICL) dari setiap baris kode atau line of code (LOC) dari perangkat lunak yang diberikan yang dilambangkan sebagai:

wics $=\sum_{K=1}^{L O C S} W I C L_{k}$

WICL dari perangkat lunak adalah fungsi dari pengidentifikasi dan operan per baris kode serta jumlah baris kode dalam perangkat lunak itu. Itu dilambangkan sebagai:

$$
W I C L_{k}=I C S_{k} /\left[L O C_{s}-k\right]
$$


Di mana LOC adalah jumlah baris dalam perangkat lunak dan ICS $_{\mathrm{k}}$ adalah informasi yang terdapat dalam program perangkat lunak untuk baris ke-k". Menghitung metrik ini bisa rumit terutama di mana perangkat lunak berisi beberapa baris kode. Selain itu, metrik ini tidak mempertimbangkan fitur berbeda dari paradigma 00 seperti pewarisan.

Pada perhitungan data metik kompleksitas yang digunakan pada penelitian yaitu tiga standar pendidikan yang dibuat dalam bpmn standar pendidikan nasional dari delapan standar nasional pendidikan yang ada ditetapkan yaitu SOP Pengembangan kurikulum, SOP Proses Pembelajaran, dan SOP Perekrutan Guru.

\subsection{Bobot Kognitif (Cognitive Weight)}

Bobot kognitif yang dimaksudkan guna mengukur upaya yang dibutuhkan dalam memahami model [8]. Bobot kognitif disimbolkan dengan huruf W. Nilai W yang rendah menjadi tujuan yang ingin didapatkan karena nilai $\mathrm{W}$ yang lebih tinggi, berarti semakin sulit untuk memahami model [8].

\begin{tabular}{|c|c|c|}
\hline BPMN structure & $\begin{array}{l}\text { BPMN } \\
\text { symbol }\end{array}$ & $\begin{array}{l}\text { Cognitive } \\
\text { weight }\end{array}$ \\
\hline Single consecutive step in a work-flow & $\Leftrightarrow \cdot \Leftrightarrow, \infty$ & 1 \\
\hline $\begin{array}{l}\text { All joins, In [33], the metric was originally defined only for business process } \\
\text { models that are well-structured. In BPMN, corresponding joins are not } \\
\text { necessary. The weight of join elements is considered as equal to the cognitive } \\
\text { weight of sequence elements. }\end{array}$ & & 1 \\
\hline XOR-split (exactly one of two branches is chosen) & & 2 \\
\hline XOR-split (exactly one of more than two branches is chosen) & & 3 \\
\hline AND-split & & 4 \\
\hline OR-split or Complex Gateway & & 7 \\
\hline Sub-process (can be used for decomposing BPMN models) & & 2 \\
\hline Start or End event & & 2 \\
\hline $\begin{array}{l}\text { Intermediate event (both intermediate events attached to the boundary } \\
\text { of activities and intermediate events within the normal flows) }\end{array}$ & & 3 \\
\hline
\end{tabular}

Gambar 2. Tabel Proposisi bobot kognitif untuk BPMN [6] 
Jurnal Riset Sistem Informasi Dan Teknik Informatika (JURASIK)

Volume 5 Nomor 2 Agustus, pp 217-226

ISSN: 2527-5771/EISSN: 2549-7839

https://tunasbangsa.ac.id/ejurnal/index.php/jurasik

\subsection{SOP Pengembangan kurikulum}

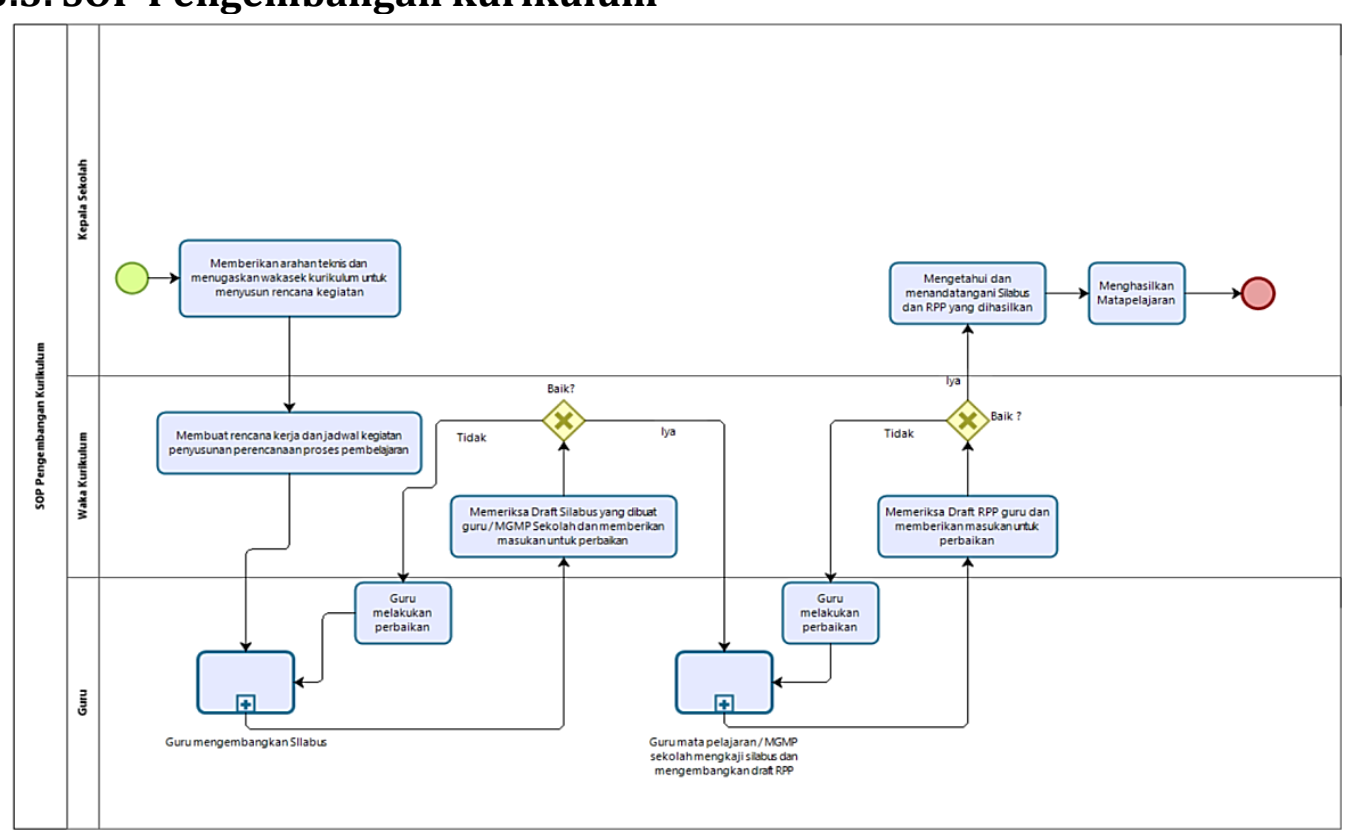

Gambar 3. BPMN SOP Pengembangan Kurikulum

Dalam standar operasional proses pengembangan kurikulum ini, memiliki 3 peranan yaitu guru, wakil kepala kurikulum dan kepala sekolah.

Tabel 1. Hasil Pengukuran BPMN SOP Pengembangan Kurikulum

\begin{tabular}{|l|l|l|l|l|l|l|}
\hline No & Metrik & Nilai & WICLk & WICS & CICM & Wc \\
\hline 1 & Size & 14 & 14 & 25,0088 & 425,1496 & 17 \\
\hline 2 & Activity Size & 10 & 5 & & & \\
\hline 3 & Resource Size & 3 & 1 & & & \\
\hline 4 & Resource Coupling & 8 & 2 & & & \\
\hline 5 & Event Size & 4 & 0,8 & & & \\
\hline 6 & Start Event Size & 1 & 0,166667 & & & \\
\hline 7 & End Event Size & 1 & 0,142857 & & & \\
\hline 8 & Intermediet Event Size & & 0 & & & \\
\hline 9 & Connector Size & 2 & 0,222222 & & & \\
\hline 10 & And Split Size & 0 & 0 & & & \\
\hline 11 & And Join Size & 0 & 0 & & & \\
\hline 12 & Or Split Size & 0 & 0 & & & \\
\hline 13 & Or Join Size & 0 & 0 & & & \\
\hline 14 & Xor Split Size & 2 & 0,142857 & & & \\
\hline 15 & Xor Join Size & 0 & 0 & & & \\
\hline 16 & Control Flow Complexity & 2 & 0,125 & & & \\
\hline 17 & Diameter & 19 & 1,117647 & & & \\
\hline 18 & Density & 0,082417582 & 0,004579 & & & \\
\hline 19 & Coefficient of Connectivity & 1,071428571 & 0,056391 & & & \\
\hline 20 & Activity Coupling & 0,933333333 & 0,046667 & & & \\
\hline 21 & Average Degree of Connectors & 0,5 & 0,02381 & & & \\
\hline 22 & Max Degree of Connectors & 2 & 0,090909 & & & \\
\hline 23 & Separability & 0,166666667 & 0,007246 & & & \\
\hline
\end{tabular}


Jurnal Riset Sistem Informasi Dan Teknik Informatika (JURASIK)

Volume 5 Nomor 2 Agustus, pp 217-226

ISSN: 2527-5771/EISSN: 2549-7839

https://tunasbangsa.ac.id/ejurnal/index.php/jurasik

\begin{tabular}{|l|l|l|l|l|l|l|}
\hline No & Metrik & Nilai & WICLk & WICS & CICM & Wc \\
\hline 24 & Sequentiality & 0,6 & 0,025 & & & \\
\hline 25 & Average Depth & & 0 & & & \\
\hline 26 & Depth Max & & 0 & & & \\
\hline 27 & Connector Mismatch & 0 & 0 & & & \\
\hline 28 & Cyclicity & 2 & 0,071429 & & & \\
\hline 29 & Token Split & -1 & $-0,03448$ & & & \\
\hline
\end{tabular}

Hasil diperoleh dari perhitungan metrik kompleksitas didapat nilai standar kompleksitasdari SOP pengembangan kurikulum yaitu 425,1496

\subsection{SOP Proses Pembelajaran}

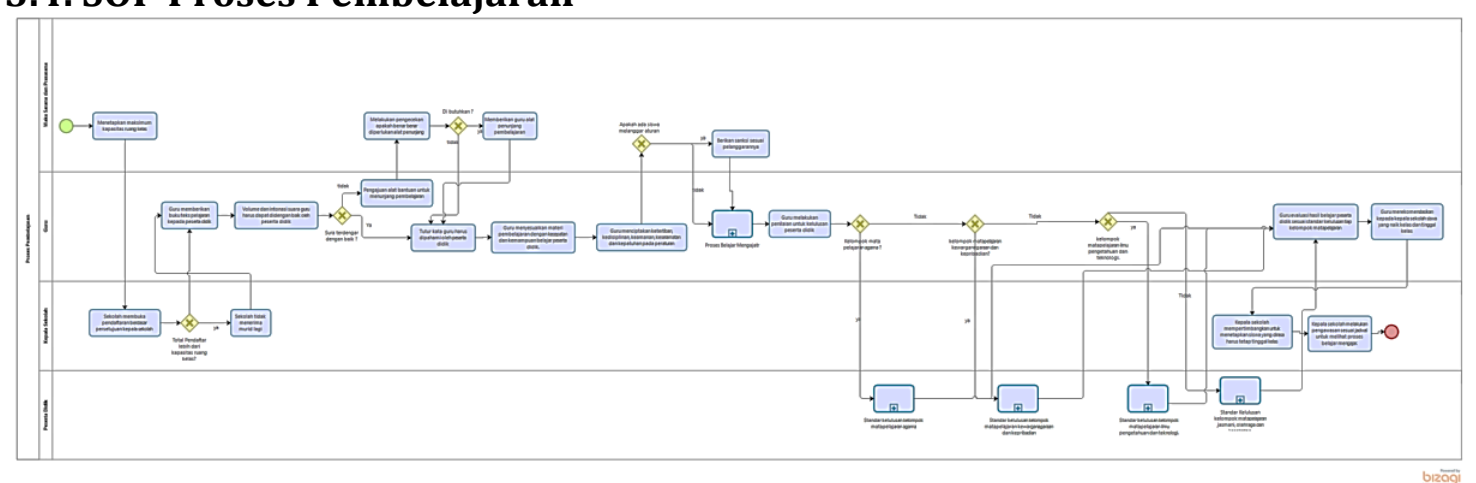

Gambar 4. BPMN SOP Proses Pembelajaran

Dalam standar operasional proses pengembangan kurikulum ini, memiliki 4 peranan yaitu peserta didik, kepala sekolah, guru dan wakil sarana dan prasarana.

Tabel 2. Hasil Pengukuran BPMN SOP Proses Pembelajaran

\begin{tabular}{|l|l|l|l|l|l|l|}
\hline No & Metrik & Nilai & WICLk & WICS & CICM & Wc \\
\hline 1 & Size & 31 & 31 & 51,00813 & 2091,334 & 41 \\
\hline 2 & Activity Size & 22 & 11 & & & \\
\hline 3 & Resource Size & 4 & 1,333333 & & & \\
\hline 4 & Resource Coupling & 17 & 4,25 & & & \\
\hline 5 & Event Size & 7 & 1,4 & & & \\
\hline 6 & Start Event Size & 1 & 0,166667 & & & \\
\hline 7 & End Event Size & 1 & 0,142857 & & & \\
\hline 8 & Intermediet Event Size & & 0 & & & \\
\hline 9 & Connector Size & 7 & 0,777778 & & & \\
\hline 10 & And Split Size & 0 & 0 & & & \\
\hline 11 & And Join Size & 0 & 0 & & & \\
\hline 12 & Or Split Size & 0 & 0 & & & \\
\hline 13 & Or Join Size & 0 & 0 & & & \\
\hline 14 & Xor Split Size & 7 & 0,5 & & & \\
\hline 15 & Xor Join Size & 0 & 0 & & & \\
\hline 16 & Control Flow Complexity & 7 & 0,4375 & & & \\
\hline 17 & Diameter & & 0 & & & \\
\hline 18 & Density & & 0 & & & \\
\hline 19 & Coefficient of Connectivity & & 0 & & & \\
\hline 20 & Activity Coupling & & 0 & & & \\
\hline
\end{tabular}


Jurnal Riset Sistem Informasi Dan Teknik Informatika (JURASIK)

Volume 5 Nomor 2 Agustus, pp 217-226

ISSN: 2527-5771/EISSN: 2549-7839

https://tunasbangsa.ac.id/ejurnal/index.php/jurasik

\begin{tabular}{|l|l|l|l|l|l|l|}
\hline 21 & Average Degree of Connectors & & 0 & & & \\
\hline 22 & Max Degree of Connectors & & 0 & & & \\
\hline 23 & Separability & & 0 & & & \\
\hline 24 & Sequentiality & & 0 & & & \\
\hline 25 & Average Depth & & 0 & & & \\
\hline 26 & Depth Max & & 0 & & & \\
\hline 27 & Connector Mismatch & & 0 & & & \\
\hline 28 & Cyclicity & & 0 & & & \\
\hline 29 & Token Split & & 0 & & & \\
\hline
\end{tabular}

Hasil diperoleh dari perhitungan metrik kompleksitas didapat nilai standar kompleksitasdari SOP Proses Pembelajaran yaitu 2091,334

\subsection{SOP Perekrutan Guru}

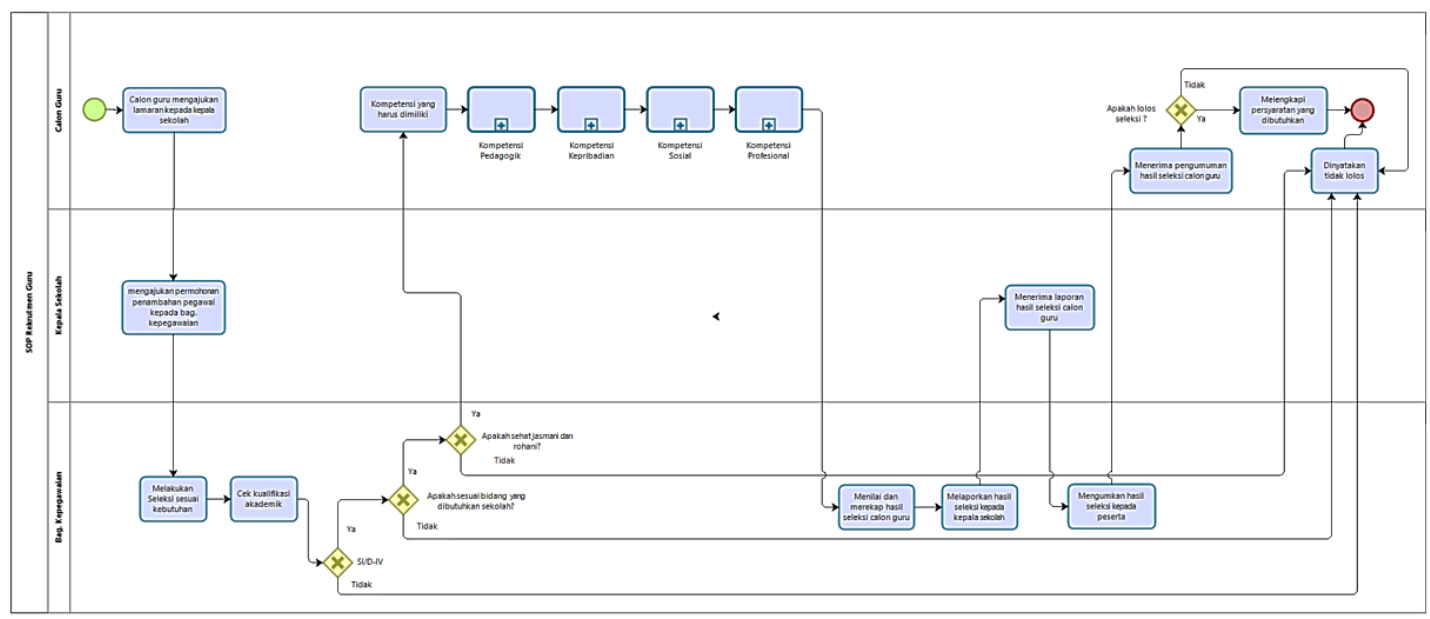

Gambar 5. BPMN SOP Perekrutan Guru

Dalam standar operasional proses pengembangan kurikulum ini, memiliki 3 peranan yaitu Bagian Kepegawaian, Kepala Sekolah dan Calon Guru.

Tabel 3. Hasil Pengukuran BPMN SOP Perekrutan Guru

\begin{tabular}{|l|l|l|l|l|l|l|}
\hline No & Metrik & Nilai & WICLk & WICS & CICM & Wc \\
\hline 1 & Size & 22 & 22 & 38,183 & 1145,49 & 30 \\
\hline 2 & Activity Size & 16 & 8 & & & \\
\hline 3 & Resource Size & 3 & 1 & & & \\
\hline 4 & Resource Coupling & 10 & 2,5 & & & \\
\hline 5 & Event Size & 6 & 1,2 & & & \\
\hline 6 & Start Event Size & 1 & 0,166667 & & & \\
\hline 7 & End Event Size & 1 & 0,142857 & & & \\
\hline 8 & Intermediet Event Size & 4 & 0,5 & & & \\
\hline 9 & Connector Size & 4 & 0,444444 & & & \\
\hline 10 & And Split Size & 0 & 0 & & & \\
\hline 11 & And Join Size & 0 & 0 & & \\
\hline 12 & Or Split Size & 0 & 0 & & & \\
\hline 13 & Or Join Size & 0 & 0 & & & \\
\hline 14 & Xor Split Size & 4 & 0,285714 & & & \\
\hline 15 & Xor Join Size & 0 & 0 & & & \\
\hline
\end{tabular}


Jurnal Riset Sistem Informasi Dan Teknik Informatika (JURASIK) Volume 5 Nomor 2 Agustus, pp 217-226

ISSN: 2527-5771/EISSN: 2549-7839

https://tunasbangsa.ac.id/ejurnal/index.php/jurasik

\begin{tabular}{|l|l|l|l|l|l|l|}
\hline No & Metrik & Nilai & WICLk & WICS & CICM & Wc \\
\hline 16 & Control Flow Complexity & 4 & 0,25 & & & \\
\hline 17 & Diameter & 19 & 1,117647 & & & \\
\hline 18 & Density & 0,045454545 & 0,002525 & & & \\
\hline 19 & Coefficient of Connectivity & 0,863636364 & 0,045455 & & & \\
\hline 20 & Activity Coupling & 1,157894737 & 0,057895 & & & \\
\hline 21 & Average Degree of Connectors & 0,25 & 0,011905 & & & \\
\hline 22 & Max Degree of Connectors & 4 & 0,181818 & & & \\
\hline 23 & Separability & 0,15 & 0,006522 & & & \\
\hline 24 & Sequentiality & 0,576923077 & 0,024038 & & & \\
\hline 25 & Average Depth & 7 & 0,28 & & & \\
\hline 26 & Depth Max & & 0 & & & \\
\hline 27 & Connector Mismatch & 0 & 0 & & & \\
\hline 28 & Cyclicity & 0 & 0 & & & \\
\hline 29 & Token Split & -1 & $-0,03448$ & & & \\
\hline
\end{tabular}

Hasil diperoleh dari perhitungan metrik kompleksitas didapat nilai standar kompleksitasdari SOP Perekrutan Guru yaitu 1145,49.

\section{SIMPULAN}

Memberikan pernyataan bahwa apa yang diharapkan sebagaimana dinyatakan dalam "Pendahuluan" akhirnya dapat diperoleh hasil dalam "Hasil dan Pembahasan", sehingga terdapat kesesuaian. Selain itu dapat juga ditambahkan prospek pengembangan dari hasil penelitian dan aplikasi lebih jauh yang menjadi prospek kajian berikutnya.

Berdasarkan hasil dan pembahasan dapat disimpulkan didapat nilai standar kompleksitas proses bisnis berdasarkan CICM SOP Pengembangan kurikulum sebesar 425,1496; SOP Proses Pembelajaran sebesar 2091,334; dan SOP Perekrutan Guru sebesar 1145,49. Selanjutnya diharapkan pada penelitian terkait bisa menghitung kompleksitas model proses bisnis lainnya.

\section{DAFTAR PUSTAKA}

[1] Mathias Weske; Business Process Management Concept, Languages, Architectures. Berlin: Springer, 2007

[2] * R. (2009). MEMBANGUN INSTITUSI SEKOLAH SEBAGAI ORGANISASI PEMBELAJAR (LEARNING ORGANIZATION). INFORMASI, 35(2). doi:10.21831/informasi.v2i2.6388

[3] Tanggo, R., \& Riady, S. C. (2014). PEMODELAN PROSES BISNIS REGISTRASI PENGISIAN KRS UNIVERSITAS SAM RATULANGI MANADO. Jurnal Teknik Informatika, 3(1). doi:10.35793/jti.3.1.2014.3925

[4] Handayani, P. W., Bressan, S., Han, D. K., \& Boucelma, O. (2012). IMPLEMENTASI SISTEM PENGELOLAAN PROSES BISNIS MENGACU PADA MIT PROCESS HANDBOOK. Jurnal Sistem Informasi, 5(2), 106. doi:10.21609/jsi.v5i2.270

[5] Subandri, M. A., \& Sarno, R. (2017). Cyclomatic Complexity for Determining Product Complexity Level in COCOMO II. Procedia Computer Science, 124, 478486. doi:10.1016/j.procs.2017.12.180

[6] Tiwari U, Kumar S. Cyclomatic complexity metric for component based software. ACM SIGSOFT Softw Eng Notes. 2014;39(1):1-6. doi:10.1145/2557833.2557853. 
Jurnal Riset Sistem Informasi Dan Teknik Informatika (JURASIK) Volume 5 Nomor 2 Agustus, pp 217-226 ISSN: 2527-5771/EISSN: 2549-7839

https://tunasbangsa.ac.id/ejurnal/index.php/jurasik

[7] Kushwaha, D. S., \& Misra, A. K. (2006). Improved cognitive information complexity measure. ACM SIGSOFT Software Engineering Notes, 31(5), 1. doi:10.1145/1163514.1163533

[8] Sadowska, M. "An Approach to Assessing the Quality of Business Process Models Expressed in BPMN". 9.57 - 77, 2015. 